\title{
THE HOSPITAL MEDICAL OFFICER
}

\author{
By Dr. Clement J. L. Wells, M.A., B.M., Ch.B.(Oxon.) \\ Hospital Medical Officer, The Radcliffe Infirmary, Oxford
}

In the last decade it has been increasingly the policy of hospitals to appoint Hospital Medical Officers, either as part or full time appointments, depending on the size of the hospital and the amount of work entailed. For long enough appointments had been made for the supervision of the health of the nursing staff, which were entrusted to members of the medical staff, but these too often had little personal continuity and a limited medical appeal.

There arose a feeling that something more comprehensive was needed. That there should be someone who, in addition to the health supervision of the Nursing Staff, would act as a liaison officer between hospital consultants and the administration; he would be conversant with the hygienic needs of the hospital and responsible for initiating investigations into the problem of ward infection. It was further felt that medical examinations should be extended to all categories of hospital personnel on their appointment, so as to avoid as far as possible the introduction of disease, more especially tuberculosis, as well as to avoid extravagant claims for sickness or disablements said to have arisen as the direct result of hospital employment. The terms of reference for such an appointment in a certain teaching hospital read as follows:

' The Hospital Medical Officer is responsible for the health of the resident medical staff, nursing staff, medical students and resident domestic staff. He is responsible for their routine medical examinations and for the reference of appropriate cases to the specialist members of the hospital staff . . . to carry out any investigations which bear on the health of the hospital staff or the hygiene of the hospital; to bring to the notice of the departments concerned any matter which he may consider of interest or importance.'

As can readily been seen, such work is of a general nature and includes clinical as well as preventive medicine. If this is to be satisfactorily carried out, a general medical education is necessary, and the best general medical education available is that of an experienced General Practitioner. No small part of his work falls outside what is strictly comprehended by medicine. He must make close contact with the administrator, the matron, the ward sisters, the catering officers, the engineers, etc. It is a necessary part of his work to know what is going on around him, and not to restrict his duties to the clinical side of his work, which is often, from his point of view, by far the most interesting and the least contentious.

The type of person likely to fulfil these requirements is one who has spent not less than ten years in good general practice, and if possible, has had previous experience of hospital service. The difficulty in finding such a person for a full-time appointment lies in the fact that he is probably already well established in general practice and is not prepared to leave it, since, amongst other things, he is capable of earning thereby twice the salary.

The question as to whether the appointment should be one of full or part-time work, must depend on the size of the hospital and the duties entailed. If possible, a part-time appointment is preferable as the choice of suitable candidates is immediately widened to include the pick of the local general medical practitioners, and this obviates the narrowing outlook that exclusively hospital work can produce. I believe that the work of a hospital of 500 to 750 beds can be satisfactorily carried out in half a day, especially where ancillary help in the shape of a secretary is available, and sector hospitals, should there be any, are not too widely dispersed.

Although it can be said that the part-time Hospital Medical Officer is covered for emergency work by the resident medical staff and the Home Sister and her staff, some of whom are always available, it is right to insist that the welfare of the hospital, as well as the nurse in training, should be the first call on his time.

\section{The Nurse}

The profession of nursing has, of course, vastly changed since the days of Florence Nightingale. The religious and humanitarian enthusiasms of the rgth century with their emphasis on 
service and sacrifice, produced a body of educated women for whom service was everything and remuneration a secondary consideration. These were a great power in giving nursing, as a profession, a new start. In the latter half of the igth century it was one of the few recognised professions open to women, and even this was looked upon as rather an eccentric outlet. In. spite of many competing fields of employment, nursing still claims the largest number of recruits, and so it must continue to do, if the demands of the hospitals and the public are to be satisfied. This is vitally important, especially at a time when public appeals for the nursing services and persistent propaganda are failing to impress, and where the public-spirited approach of the individual does not tend to increase. One thing is clear, and that is that when a girl decides to take up nursing, the hospital at which she trains should have a high standard of regard for her service and create the best possible facilities for the supervision of her physical and psychological welfare.

\section{The Physical Care of the Nursing Staff}

The King Edward Fund has produced 'A Memorandum on the Supervision of the Health of Nurses.' This is a memorandum of importance and has been produced by those who have had much experience of the problems involved. The Fund has also evolved a hospital record form which serves admirably the purpose of keeping, in sufficient detail, the health and sickness record of nurses during the three or four years they are in training. The advantage of adopting a standard form in hospitals is that it can be filed easily and tidily when a nurse passes from one hospital to another and where information is collected on forms with a similar questionnaire, extractions for research purposes are made more easily. Some Medical Officers examine a nurse only on admission and on passing out, unless their notice is called to some abnormal pathological or radiological finding, or the nurse herself wishes to report sick. If the Medical Officer repeats both physical examination and such tests as are applicable in six months from the date of examination on entry, then annually, as long as the nurse remains in hospital, he will discover many ills, psychological and physical, which he would otherwise have missed.

An explanation should always be given to a nurse of the rationale of the tests and protective steps that are undertaken, pointing out that their object is to make her occupation safer, both for her and for her patients.

\section{Pulmonary Tuberculosis}

I have no doubt in my own mind that it is the regular surveillance of the chest by radiological examination that is the most important part of the investigations. The proportion of pulmonary tuberculosis is higher in the nursing profession than amongst the average population, since nurses are more intimately thrown into contact with infected persons. It is interesting to note that the incidence of pulmonary tuberculosis is less in sanatoria than in general hospitals, the reason being that fuller precautions are taken against the disease where it is known to be present than in the wards of the general hospital, where it is presumed to be absent. It is tuberculosis, before its clinical recognition rather than after, that is a danger from the point of view of the infection of others. The answer as to how often a nurse's chest should be $\mathrm{X}$-rayed is difficult, and must, of course, be decided by the individual Hospital Medical Officer concerned. The commonly accepted periodicity is on entry, in six months time and thereafter annually; but with the great saving of cost experienced in the use of the miniature camera, one is tempted to shorten the annual period to six-monthly throughout their course of training.

The value of radiography, as against the stethoscope, in early diagnosis is, I think, fully established. To say that it has superseded the stethoscope as a diagnostic weapon is an exaggeration, but I think only a slight one. Early tuberculous changes in a chest are shown by radiography, which are quite unrecognisable through the stethoscope, and this early recognition is of supreme importance and a great saving in the time needed for recovery. The question as to whether, at times, radiographic appearances do not lead into errors of diagnosis can, I think, only be answered by saying that the more experienced the radiologist, the fewer will be the errors of interpretation.

Another precaution that should be insisted upon, and has now been almost universally adopted, is the vaccination of Mantoux negative reacters. The day has passed when it was considered enough to recognise the Mantoux negative population and watch for their gradual conversion during training, and, after conversion, take certain special precautions. Vaccination has now gone beyond the experimental stage, although it is not for me to assess its exact immunizing value. How far have better food and living conditions effected the general improvement that has taken place? In the overall picture, I am persuaded of the value of vaccination, and now always employ it. The adenitis or occasional abscess formation which may arise is too infrequent to make one regret this decision. A disconcerting occurrence is the reversion of an artificially produced positive Mantoux reaction at the end of a year or two. It 
is a matter for individual opinion whether these nurses should be revaccinated. There is experimental evidence in animals that, following vaccination, with some vaccines at any rate, the increased resistance to infection against virulent tubercle bacilli is not conterminous with tuberculin sensitivity, but may last for a considerably longer period. It is recognised that some individuals do revert early. It is quite possible that these persons who can eliminate rapidly from their body the attenuated tubercle bacilli used in the vaccine, have the same power of dealing effectively with a virulent infection. If, in the future, the procedure could be simplified, and the follow-up less exacting, it would be much appreciated by all concerned. Lastly, keep the disease out of the wards as far as possible and insist that all staff who feel unduly tired, or know that they are losing weight, or those who appear ' off colour' to others, should report to the Medical Officer for physical examination, since amongst the many causes of a debilited condition is that of early tuberculosis. It may seem that the subject of tuberculosis has been over-emphasised. I do not believe this to be so. It is not a quickly curable disease; it is not even always curable. As has rightly been said, the only certain thing about the prognosis of tuberculosis is its uncertainty, and it tends to leave both social and psychological scars behind it which are not easily eradicated.

Its early recognition presents so many difficulties that one is only too glad to use all possible aids that have been discovered to this end. Tuberculosis can progress far along its course without pain and without symptoms which attract the sufferer's notice. It is inadvisable to let it be far from the thoughts of those who have the responsibility of the health of the student nurse. The fact that a number of cases which show radiological evidence of a primary complex would have recovered spontaneously and without the rest which is now considered desirable, should not lead to the neglect of these precautions. Whilst on this subject, it is noteworthy that a higher proportion of student nurses is Mantoux negative than was formerly the case. Amongst other reasons, one is surely the almost universal purveying of pasteurised and non-tuberculous milk.

\section{Resistant Bacteria}

The problem of the increases in the resistant strains of bacteria present in hospitals, owing to the extensive use of antibiotics, calls for serious recognition. It is increasingly found in hospital that infections of the skin, nose or throat are due to a staphococcus which is highly resistant to penicillin, streptomycin, aureomycin and other antibiotics and serious therapeutic problems may arise in cases where chests, or clean surgical cases, as examples, become infected by carrier nursing staff. It is often the delay in recognising that an infection is due to resistant bacteria that increases the danger to the patient. As the problem becomes an increasingly pressing one, more attention will have to be paid to careful dust extraction and sterilization. I am convinced from ordinary observation and the evidence of a slit sampler, that brooming in any form is strongly to be deprecated as always inefficient, and now dangerous, since all hospitals contain dust contaminated by resistant bacteria. There are many forms of vacuum cleaner from which a choice can be made.

\section{Nursing of the Sick Nurse}

There are many methods adopted for the accommodation of the sick nurse. Some hospitals allocate a sick bay containing separate cubicles, some a ward or part of a ward in the hospital. Others again nurse their cases at the end of the existing hospital wards or in adjacent side wards. Ideally, the Medical Officer should have a block of separate rooms with a consulting room and surgery attached to one end of it and the Home Sister's office at the other, the whole being situated in the Nurses' Home. Surrounded by consultants of every kind, the Hospital Medical Officer will seek their help and advice more frequently than under other circumstances, although perhaps there are as many fall-traps in specialized knowledge as there are in general knowledge; perhaps more.

One might have assumed that the bed accommodation of a sick bay would have been worked out on a percentage basis of the number of nurses in training. Perhaps the officials at Whitehall are too wise. Sick bay accommodation is less strained during the summer months than during the winter, and since available bed accommodation is the crying need of all hospitals at the present time, and will continue to be so for some years to come, to stipulate a fixed number of beds (which might, under certain circumstances, and for a considerable length of time, remain empty) would be a grave error from the point of view of economical planning. It must, however, be accepted by all who have the arrangement of admissions to hospital, harassed as they may be, that the claim of the nursing staff is indisputably pre-eminent, not only in theory but in practice.

I have found that 1.5 per cent. permanent accommodation, with power to expand and with no reference to epidemic illness, has provided sufficient for my needs. Whether nursing staff or patients in general like single accommodation 
better than ward accommodation is not easy to decide. We all think we like single room accommodation until we are placed in wards, where the average human finds to his surprise that he is happier in closer contact with his fellow humans than in isolation. A ward is certainly easier to nurse and to observe, but as so many cases of sickness amongst the nursing staff are infectious, single cubicles are to be preferred.

\section{Home Sisters}

The choice of a Home Sister calls for careful consideration. In most hospitals it is, or was, considered a stepping-stone to higher things, a post that must be obtained in the ascent of the administrative ladder. The allotted duties usually embrace much more than the supervision of the health and sickness of the nursing staff, and include the supervision of the dining room and recreation room, the care of linen and cutlery, and often the supervision of the domestic staff. In fact, most of the things which affect the life and welfare of the nurse in the nurses' home. It is, however, essential that she, or they, should hold the confidence and, if possible, the affection of the nursing staff. A nurse will confide nothing to a home sister who is known to pass private and unimportant details on to others and punctiliously report the minor delinquencies which engulf the young. It is no part of a home sister's work to discourage a nurse from reporting sick, and it behoves the Hospital Medical Officer to make it quite clear that nothing is to be allowed to come between him and any nurse who wishes to report sick, however trivial the complaint may appear. Further than this, if he discovers anything which leads him to suspect that this is the case, he must immediately intervene. Women are often not kindly disposed to others over whom they exert authority, sometimes for reasons which are obvious to the onlooker. The nurse in training is placed in a difficult position. She has recently left school, with its restrictions, to enter what she considered to be a world of freedom, but a nurse's training is not a world of freedom and is not comparable to a college training in many of its aspects. Discipline must perforce be stricter; for a nurse, punctuality, accuracy, cleanliness and observation may, by their neglect, carry the gravest of consequences, and many things cannot be allowed in the student nurse which might be passed over without serious comment in other student groups.

Strict discipline is part of a nurse's training, as it is of a soldier or sailor, and if she is not prepared for it she should not enter the profession; but it is because discipline must be enforced strictly on duty that freedom and relaxation should be encouraged at other times. This is now being understood and appreciated. I doubt if the majority of young women object to discipline, except in theory, but there is a world of difference in the way, and by whom, the discipline is exercised. Again and again one is driven back to the personality of those responsible for the training of this young adolescent group 18 to 21 . If you cannot allow the student nurse freedom of action to the extent that is possible to other groups of the same age, you should seek to give in exchange something which the others have not got. The competing market is strong and becomes stronger every year. In nursing, however, there is already one big asset in hand, and that is the absorbing interest and variety of the work and its permanent use in after-life. Feed them well, perhaps extra well, house them well and rest them well. The larger hospitals, whenever at all possible, should have good playing fields, and I feel that professional tuition in games from a Physical Training Instructress should be considered. Being professionally coached and made proficient in games in as far as it is possible, is a social asset which would often be much appreciated by those whose upbringing has not previously permitted it. Supply a swimming pool, if possible, give them well furnished common rooms supplied with papers and periodicals, a good recreation room with a well lighted stage. Make their off-duty times as full of healthy interest and relaxation as possible, without impinging on their freedom. Last, but not least, a good chaplain is essential. In many nurses the underlying urge to training is a religious one, and this must not be neglected or discouraged. If it is, it will be at the risk of their losing direction and enthusiasm, and this will be followed, inevitably, by a loss of efficiency. Patience, gentleness, kindness, sacrifice and service are among the virtues having a common origin which lies outside human nature as such, but they are as essential to the make-up of a good nurse as the contents of her textbooks. If this is true, a good chaplain must be, in his way, as important as a good sister tutor is in hers.

\section{Private Interviewing of Nurses}

From time to time requests are made by a nurse in training to be seen alone. Such confidential consultations cannot be refused. I feel, however, they are not to be encouraged, either from the point of view of the nurse or of the Hospital Medical Officer, as they create a mysterious and unhealthy atmosphere. Further, information which is given in strict confidence, cannot be used and must remain a secret between the two parties, which is often not the best way of resolving a problem. However, there are some problems 
where a confidential discussion, as a preliminary, is desirable. Unless a special request is made by the nurse, I always interview and examine in the presence of the Home Sister. I make an exception in the case of Ward Sisters, whom I always interview alone.

\section{Clothing}

The question of a nurse's uniform should possibly not be discussed by a man, but it is as a man that one is often struck by the drab and unattractive appearance which many of these uniforms present. In byegone days, an attractive uniform has, many a time, decided for an individual the regiment of his choice. Much more so, then, must this apply to women.

I have never been able to discover any useful function for the vestigial remains of a head covering which is seen in the caps worn in the present day, and I should have felt that a more attractive uniform could be designed without them.

Should not a greater colour difference be made between first, second, third and fourth year nurses, so that there is an increased desire to press on? Anyway, a nurse wants to look her best when she is doing her work, in the same way as she wishes this when she is off duty, and I feel she is not always given the opportunity of doing so.

\section{Leaders}

Unless there are good leaders, no hospital will go ahead. All the points discussed are secondary to this in importance. From the Matron down to the Domestic Supervisor, the heads of wards and department; all should be chosen for their power of leadership, far more than for their scholarship. This is a quality which should be noted and given scope for expression throughout a nurse's training, having always in view the needs of the hospital at a future time. Any administrator or matron who seeks to wield power from their own hands, without the delegation of duties and real responsibility to those under them, will never have a good hospital. Those in quite subsidiary positions must be given the full responsibility of their particular jobs and encouraged to assume the dignity that goes with responsibility. No hospital is healthy or satisfactorily administered which has a series of 'yes men,' and women, in places of responsibility, nor from such an organisation will you ever get loyalty. I am not at all convinced that the old Medical Superintendent, with his intimate knowledge of his hospital, was not frequently a person of great value, and by his departure hospital administration has not been seriously weakened, especially in these days of government control.

\section{The Hospital}

The Hospital Medical Officer's work extends to many departments, other than that of the care of the health of the hospital personnel. He should, for instance, know more than just the rudiments of hygiene and sanitation, and he should keep an open eye on the kitchen and the laundry as well as on the hospital buildings. It is here that he should work in close co-operation with the administrators, and they will frequently help one another by supplementing the other's knowledge. He should feel reproached when he is in ignorance of matters relating to these subjects, when they are brought forward for discussion. I am not suggesting that his knowledge can be complete, nor is this necessary in these days of specialization. He will have at his elbow pathologists, medical officers of health, sanitary inspectors, pest officers, whose expert knowledge can be called upon at any time, but like all experts; they have often evolved complicated techniques, as unnecessary as they are financially costly. It is this that makes it desirable that there should be attached to every hospital a medical man with an all-round knowledge of medicine, surgery, gynaecology, hygiene and tact. Few consultants have either the time, knowledge, or inclination to record the needs of departments other than their own.

There should be in every hospital a Committee established to deal with ward infections, when they arise, and matters of general concern in the establishment and maintenance of healthy and hygienic conditions in the wards and amongst the staff and patients. The Hospital Medical Officer should act as correlating officer, calling together members of the hospital staff whose special knowledge will assist in the solution of the problem which has arisen. Probably no specialist will be prepared to give an authoritative ruling on the problem as a whole, but will do so on those aspects of which he has special knowledge. A bacteriologist, a medical officer of health, an engineer, an architect, a surgeon or physician, may all have to be consulted on one single incident.

The causes and solution of an outbreak of cross infection in a ward are not entirely the department of the pathologist, any more than an outbreak of food poisoning is entirely that of the cook. It is not that the Hospital Medical Officer is a repository of all the learning of all the specialists he consults. He consults them because he is not, but it requires little depth of knowledge to know whom to consult and it then remains his responsibility to carry out, as far as is possible, such recommendations as are made.

I think it is unnecessary to give examples of the type of problem which arises in hospital, as they are familiar to all of us: outbreaks of dysentery, 
staphylococcal and streptococcal infections, exanmatous fevers, food poisoning, faults in sterilizathetion, kitchen hygiene, infestation by flies or insects, and the many other ills which all institutions are heir to.

\section{Medical Students}

Medical students have started their training on entirely different lines from those of student nurses. They have always been masters of their own fates and may they always remain as such. A Director of Clinical Studies makes no attempt to discipline medical students as a matron does her nurses. The vast majority live out, and their social and hospital activities are entirely separated. However, they have this in common, that they are both exposed to the same disease risks, although possibly less intimately. For this reason, the same precautions should be taken. Here again, it is the respiratory system which holds the forefront of the picture and for that same reason, regular radiology, the Mantoux reaction, and subsequent vaccination where necessary, must be carried out.

Are nurses and medical students more hypochondriacal than the average lay person? It would be strange if they were not, as studying and living with disease they become fearful as well as curious. They see death as neither a respecter of persons nor of age. They see the results of faulty and late diagnosis, and often experience a shock in the discovery of incurable disease. Again, the tempo of a student's work is, I am certain, higher than it was 30 years ago. They take themselves and their work much more seriously, often to the extent of embarrassing their general health. The path of the Hospital Medical Officer is not made easier by the fact that as a class they are persuaded of the complexity. of their conditions, and are as convinced of the fallibility of the general practitioner's opinion as they are of the infallibility of the consultant's. They have to be saved from themselves, and the consultant from having to deal with minor ailments, at which form of medicine and surgery he does not always excel. An annual overhaul of all medical students should take place, although perhaps the examination questionnaire need not be so detailed as that of the nurse in training. Those who are housed in a hostel in or near the hospital can be medically attended by the Hospital Medical Officer in sickness, but where distance is a consideration there is seldom time to pay domiciliary visits, and these should be carried out by an outside practitioner of their choice.

\section{Domestic Staff}

This important section of the hospital should be examined for physical fitness before they are taken on the staff. They are not usually of the highest grade, either physically or mentally, and yet the physical demands made on them are considerable. They can be an exacting class to supervise medically, as the suspicion that the Hospital Medical Officer's main function is to make light of their ailments and return them to duty without delay seems inherent in their approach to him. An added complication lies in the number of Displaced Persons at present employed. These strangers in a strange land, highly strung by nature, seek too often to find physical expression for their psychological ills. In this class, again, the chest X-ray is an essential and nowhere should it be more strongly enforced than in members of the kitchen staff.

The aversion of some, especially the middle-aged to medical examination, is quickly disappearing as it has now become the recognised preliminary to employment, especially in hospital work, and is known to have been instituted as a public health measure for the prevention and earlier recognition of disease. Unless I have had some good reason for doing so, I have not forced this examination on some of the old employees of the hospital who are the survival of a fairer and more reckless age.

\section{Clerical Help}

Where the number of personnel in a hospital group, for which the Hospital Medical Officer is responsible, approaches $\mathrm{I}, 000$, a secretary would seem quite essential. Records must be maintained conscientiously, or not at all; dates for routine medical examinations adhered to, the appointments made for new members of the staff to be examined and a hundred and one other routine arrangements at which the average doctor conspicuously fails. Even so, it is surprising how often mistakes are made and matters overlooked. Examples of this are frequently seen in the way heads of departments will fail to notify new staff, and such an oversight seems unfairly penalized by the frequency with which these members of the staff turn out to be medically unfit on a late examination. The legal position at the present time has to be watched, since personnel accepted for work cannot be discharged at will.

I have made no attempt to set out in detail the whole field of work which falls to the Hospital Medical Officer. I have drawn attention to certain aspects which seem to me to be important and which have been brought home to me by my own individual experiences. To others, different aspects of the work may have presented themselves, and it would be of more than passing interest if these were more fully known. 